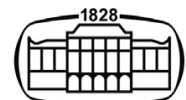

AKADÉMIAI KIADÓ

Journal of Behavioral

10 (2021) 1, 42-54

DOI:

$10.1556 / 2006.2021 .00009$

(c) 2021 The Author(s)

\section{FULL-LENGTH REPORT}

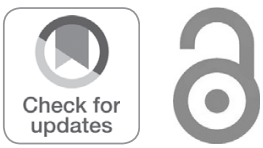

\title{
Five-year follow-up on a sample of gamblers: predictive factors of relapse
} Addictions

\section{MARIE GRALL-BRONNEC ${ }^{1,2 *}$ (1), MORGANE GUILLOU-LANDREAT ${ }^{3,4}$, JULIE CAILLON ${ }^{1,2}$, CAROLINE DUBERTRET ${ }^{5,6}$, LUCIA ROMO ${ }^{7,8}$, IRÈNE CODINA ${ }^{9}$, ISABELLE CHEREAU-BOUDET ${ }^{10}$, CHRISTOPHE LANCON ${ }^{11}$, MARC AURIACOMBE ${ }^{12,13,14}$, JEU-GROUP $^{\dagger}$, JEAN-BENOIT HARDOUIN ${ }^{2,15}$, and GAËLLE CHALLET-BOUJU ${ }^{1,2}$}

\author{
${ }^{1}$ Department of Addictology and Psychiatry, CHU Nantes, Nantes, France \\ ${ }^{2}$ Université de Nantes, Université de Tours, Inserm U1246, Nantes, France \\ ${ }^{3}$ Department of Addictology, CHU Brest, Brest, France \\ ${ }^{4}$ Université de Bretagne Occidentale, ERCR SPURBO, Brest, France \\ ${ }^{5}$ Institute of Psychiatry and Neurosciences, INSERM UMR1266, Université de Paris, Team 1, Paris, \\ France \\ ${ }^{6}$ Department of Psychiatry, AP-HP, Louis Mourier Hospital, Colombes, France \\ ${ }^{7}$ Department of Psychology, Université Paris Nanterre, EA 4430 CLIPSYD, Nanterre, France \\ ${ }^{8}$ CMME, GHU Paris Psychiatrie et Neurosciences, INSERM U1266, Paris, France \\ ${ }^{9}$ Marmottan Medical Center, GPS Perray-Vaucluse, Paris, France \\ ${ }^{10}$ Psychiatry Department, CHU Clermont-Ferrand, Clermont-Ferrand, France \\ ${ }^{11}$ Centre d'études et de recherches sur les services de santé et la qualité de vie, Université de la \\ Méditerranée, Marseille, France \\ ${ }^{12}$ University of Bordeaux, Bordeaux, France \\ ${ }^{13}$ Addiction Team, Sleep Addiction and Neuropsychiatry Laboratory (SANPSY), CNRS USR 3413, \\ Bordeaux, France \\ ${ }^{14}$ Pôle Addictologie, $\mathrm{CH}$ Charles Perrens and CHU de Bordeaux, Bordeaux, France \\ ${ }^{15}$ Methodology and Biostatistic Department, CHU Nantes, Nantes, France
}

Received: September 15, 2020 • Revised manuscript received: January 12, 2021 • Accepted: February 06, 2021

Published online: April 1, 2021

\section{ABSTRACT}

${ }^{\dagger}$ Members of the JEU-Group: Marie Grall-Bronnec, Gaëlle Challet-Bouju, Jean-Luc Vénisse, Lucia Romo, Cindy Legauffre, Caroline Dubertret, Jean Adès, Irène Codina, Marc Valleur, Marc Auriacombe, Mélina Fatséas, Jean-Marc Alexandre, Pierre-Michel Llorca, Isabelle Chéreau-Boudet, Christophe Lançon, David Magalon, Amandine Luquiens, Michel Reynaud.

*Corresponding author. E-mail: marie.bronnec@chu-nantes.fr

Background and Aims: Few studies have been conducted on the long-term evolution of gambling disorder (GD). The aim of this study was to identify factors that could predict GD relapse. Methods: Data were part of a dataset from a large 5-year cohort of gamblers who were assessed at inclusion and each year thereafter. Participants were recruited from an outpatient addiction treatment center, from various gambling places and through the press. For this specific study, inclusion criteria included (i) transitioning from GD to recovery at a follow-up time and (ii) undergoing at least one follow-up visit afterwards. Participants were evaluated using a structured clinical interview and self-report questionnaires assessing sociodemographic, gambling and clinical characteristics. "Relapse" was defined as the presence of GD (according to the DSM-5) at the $\mathrm{N}+1^{\text {th }}$ visit following the absence of GD at the $\mathrm{N}^{\text {th }}$ visit. A Markov model-based approach was employed to examine predictive factors associated with relapse at a subsequent follow-up visit. Results: The sample consisted of 87 participants, aged 47.6 years $(\mathrm{sd}=12.6)$, who were predominantly male (65\%). Among the participants, 49 remained in recovery, whereas 38 relapsed. Participants who reported not having experienced at least one month of abstinence and those with a low level of self-directedness at the previous follow-up visit were more likely to relapse. Conclusions: Our findings suggest the existence of factors that are predictive of relapse in individuals with GD 
who had previously achieved recovery. These results can inspire the development of measures to promote long-term recovery.

\section{KEYWORDS}

Gambling disorder, recovery, relapse, predictive model, Markov, self-directedness

\section{INTRODUCTION}

Gambling disorder (GD) is defined as persistent and recurrent gambling behavior leading to clinically significant impairment or distress (APA, 2013). The key features of GD include the loss of control over gambling and continued gambling behavior despite significant harmful consequences.

There is abundant literature on how to distinguish problem gambling from social gambling (LaPlante, Kleschinsky, LaBrie, Nelson, \& Shaffer, 2009; Petry, 2003; Sharpe, 2002; Welte, Barnes, Wieczorek, Tidwell, \& Hoffman, 2007; Welte, Barnes, Wieczorek, Tidwell, \& Parker, 2004) and about the factors associated with the development of GD (Blaszczynski \& Nower, 2002; Nower \& Blaszczynski, 2017; Potenza et al., 2019). However, only a few studies on the long-term evolution of gambling patterns have assessed transitions from one state to another, including relapse (Abbott, Romild, \& Volberg, 2018; Billi, Stone, Marden, \& Yeung, 2014; el-Guebaly et al., 2015; Mazar, Volberg, Williams, Stanek, \& Zorn, 2019). In particular, Slutske et al. concluded that gambling problems are often transient and episodic rather than continuous and chronic (Slutske, Jackson, \& Sher, 2003).

Apart from clinical trials that consider relapse as an outcome measure (see, for instance, Cowlishaw et al., 2012; Goslar, Leibetseder, Muench, Hofmann, \& Laireiter, 2019), follow-up studies examining predictors of relapse are relatively scarce. In particular, to our knowledge, there is no gambling relapse prevention model constructed similar to that proposed by Marlatt and Gordon regarding alcohol use, which is based on both immediate determinants and covert antecedents (Marlatt \& Gordon, 1985). However, several factors have been identified among clinical samples: single marital status (Aragay et al., 2015), young age (Echeburua, Gomez, \& Freixa, 2017), low income and small amounts of money spent on gambling (Aragay et al., 2015; Echeburua et al., 2017), gambling urges (Oei \& Gordon, 2008; Smith et al., 2015), gambling-related cognitions (Mallorqui-Bague et al., 2019; Oei \& Gordon, 2008; Smith et al., 2015), psychopathological distress (Muller et al., 2017; Sander \& Peters, 2009), impulsivity (Mallorqui-Bague et al., 2018, 2019), and poor cognitive flexibility (Mallorqui-Bague et al., 2018). In a naturalistic sample of pathological gamblers who had recently quit gambling, a history of gambling treatment and a current alcohol use disorder predicted relapse from a minimum 6-month period of abstinence (Hodgins \& elGuebaly, 2010).
In addition to the relative scarcity of studies related to relapse, other limitations can be noted. The composition of their samples is heterogeneous (including, for instance, naturalistic sample [Hodgins \& el-Guebaly, 2010], Gambling Anonymous members [Oei \& Gordon, 2008], patients seeking treatment for GD [Muller et al., 2017], patients with schizophrenia seeking treatment for GD [Echeburua et al., 2017]). The length of follow-up periods is also highly variable (from 3 months [Mallorqui-Bague et al., 2019] to 5 years [Hodgins \& el-Guebaly, 2010]). Moreover, it is important to emphasize the current absence of a consensual definition of relapse.

For some authors, gambling relapse is defined as "the occurrence of any gambling episode with bets" (Granero et al., 2020; Hodgins \& el-Guebaly, 2004; Mallorqui-Bague et al., 2018), as "more than two episodes of gambling or one gambling episode with loss of control" (Aragay et al., 2015) or as "three or more lapse episodes" (Echeburua et al., 2017), while for others, it "involves more than simply a single incidence of resumption of the target behavior" and thus differentiates between a "lapse" (a single episode) and a "relapse" (multiple episodes) (Ledgerwood \& Petry, 2006). According to Gambling Research Australia (2010), "relapse is the re-emergence of gambling that may cause harm to the individual, significant others or the community after a period of abstinence or controlled gambling" (Battersby, Oakes, McLaughlin, \& Baigent, 2010). We agree with this definition, as it has been demonstrated that controlled gambling could represent a viable goal for some disordered gamblers (Ladouceur, Lachance, \& Fournier, 2009).

As a consequence, the predictors of gambling relapse are not yet well established. The JEU cohort study was designed to identify the determinants of key state changes in gambling practice, including relapse. Data collected comprised sociodemographic, gambling and clinical characteristics with the selection of variables resulting from a compromise reached through discussions between experts involved in the project, a review of the literature and the need to minimize the duration of the assessment (Challet-Bouju et al., 2014). The aim of the present work was to determine factors that could predict relapse in GD with a specific focus on dynamic variables (i.e., that can evolve over time) so that a change at a visit $\left(\mathrm{N}^{\text {th }}\right.$ visit) can predict a potential relapse at the next visit $\left(\mathrm{N}+1^{\text {th }}\right.$ visit). Indeed, several models emphasize relapse as a transitional process or a series of events that unfold over time (Larimer, Palmer, \& Marlatt, 1999). Identifying predictors of relapse at the $\mathrm{N}^{\text {th }}$ visit could permit intervention and better prevent the risk of relapse at the $\mathrm{N}+1^{\text {th }}$ visit.

\section{METHODS}

\section{Dataset}

For the present study, we used the dataset from the multicenter JEU case-control cohort (ClinicalTrials identifier: NCT01207674) (for more details, see Challet-Bouju et al., 2014). The JEU cohort was implemented between April 2009 and September 2016 and consisted of two phases. 
Phase 1 aimed to enroll and describe a large sample of gamblers $(n=628)$ with gambling patterns of varied severity (nonproblem gamblers, problem gamblers without treatment and problem gamblers in treatment). Gamblers of both sexes who reported gambling on at least one occasion over the previous year and aged 18 to 65 were eligible for the JEU study. Participants were recruited between April 2009 and September 2011 from various gambling places (casinos, cafés, smoke shops, etc.) $(n=195)$, through the press $(n=227)$, and from seven outpatient addiction treatment centers, provided that they had started treatment less than six months before $(n=206)$. This period length was fixed because the mean duration of cognitive-behavioral interventions is less than 6 months (Gooding \& Tarrier, 2009). The exclusion criteria included severe cognitive or communication impairment, guardianship and gambling treatment received at some point in life (except for the participants enrolled in addiction treatment centers). All participants underwent a baseline assessment immediately after inclusion, which applied a face-to-face clinical semistructured interview and a set of standardized self-report questionnaires.

Phase 2 aimed to explore, over a five-year prospective follow-up period, the differential evolution of gamblers over the long term. The study was intended for all nonproblem gamblers, all problem gamblers without treatment and problem gamblers in treatment recruited by the coordinating center (problem gamblers recruited by other addiction treatment centers have not been followed because of funding constraints, $n=105$ ). A significant portion of the initial sample refused to participate in the follow-up study $(n=213,40.7 \%)$. Therefore, 310 gamblers actually participated in Phase 2. They were then followed up for 5 years, and the follow-up interview was offered by phone or in person depending on the availability and preferences of the participant. Well-trained and experienced staff members performed all of the assessments.

\section{Participant selection for the present analysis}

Of the 628 gamblers participating in Phase 2, we included in the present work only those for whom a relapse could be observed, i.e., gamblers who had already been diagnosed with GD, transitioned from the condition of GD to the condition of no GD at a follow-up time and completed at least one follow-up visit afterwards. After applying these inclusion criteria, the sample consisted of 87 gamblers, of whom 12 were "nonproblem gamblers", 53 were "problem gamblers without treatment" and 22 were "problem gamblers in treatment" at baseline. The participant selection method applied is described in the flow chart provided in Fig. 1. A schematic representation of the follow-up study is presented in Fig. 2.

\section{Measures}

Of the measures available in the JEU cohort dataset, we selected the following as relevant for the present analysis.

\section{- Sociodemographic characteristics}

We collected information on age, sex, marital status (living as a couple or not), education level (completing Grade 12 or not), professional activity (having a job or not), and income level (earning minimum wage or not).

- Gambling characteristics

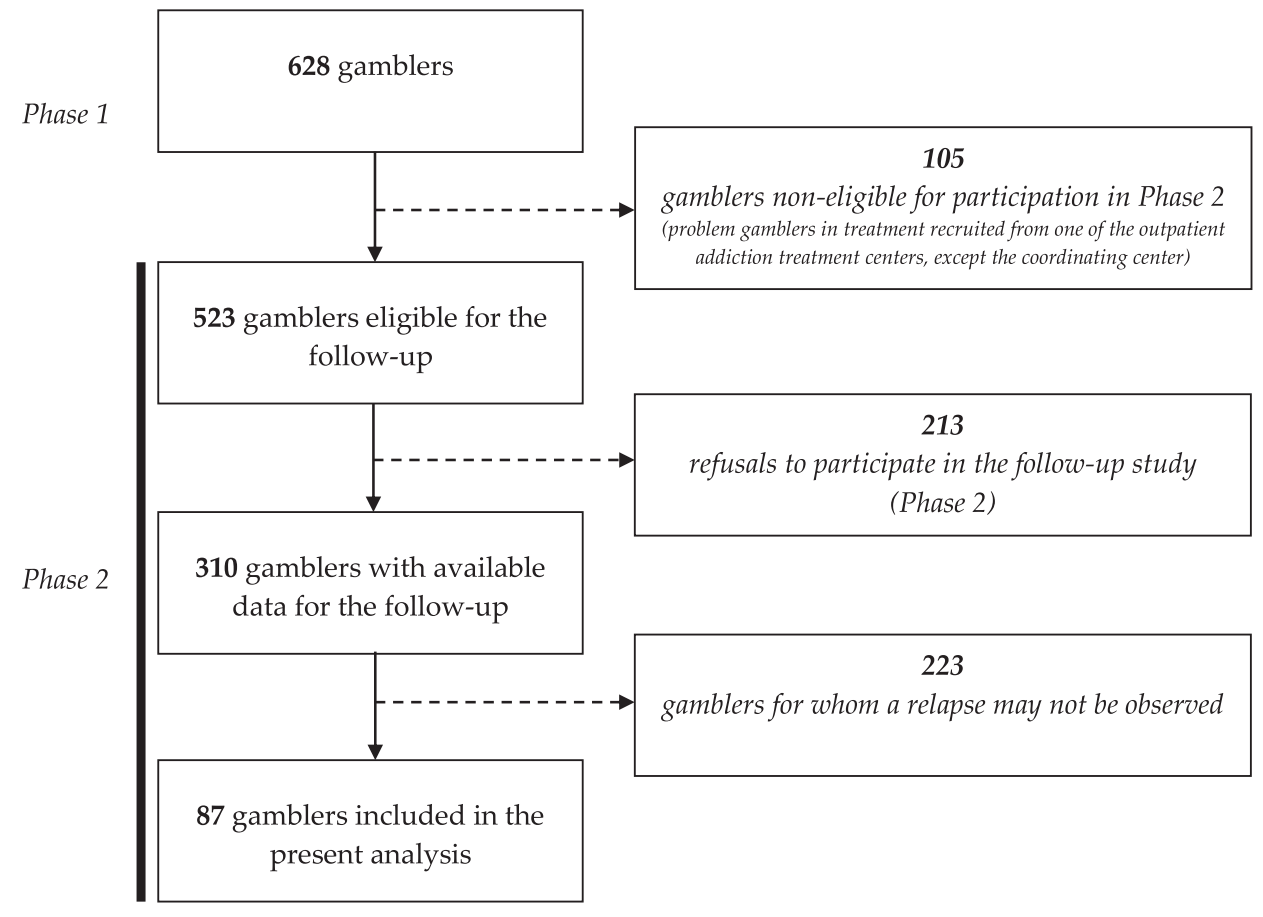

Fig. 1. Flow chart of participant selection 


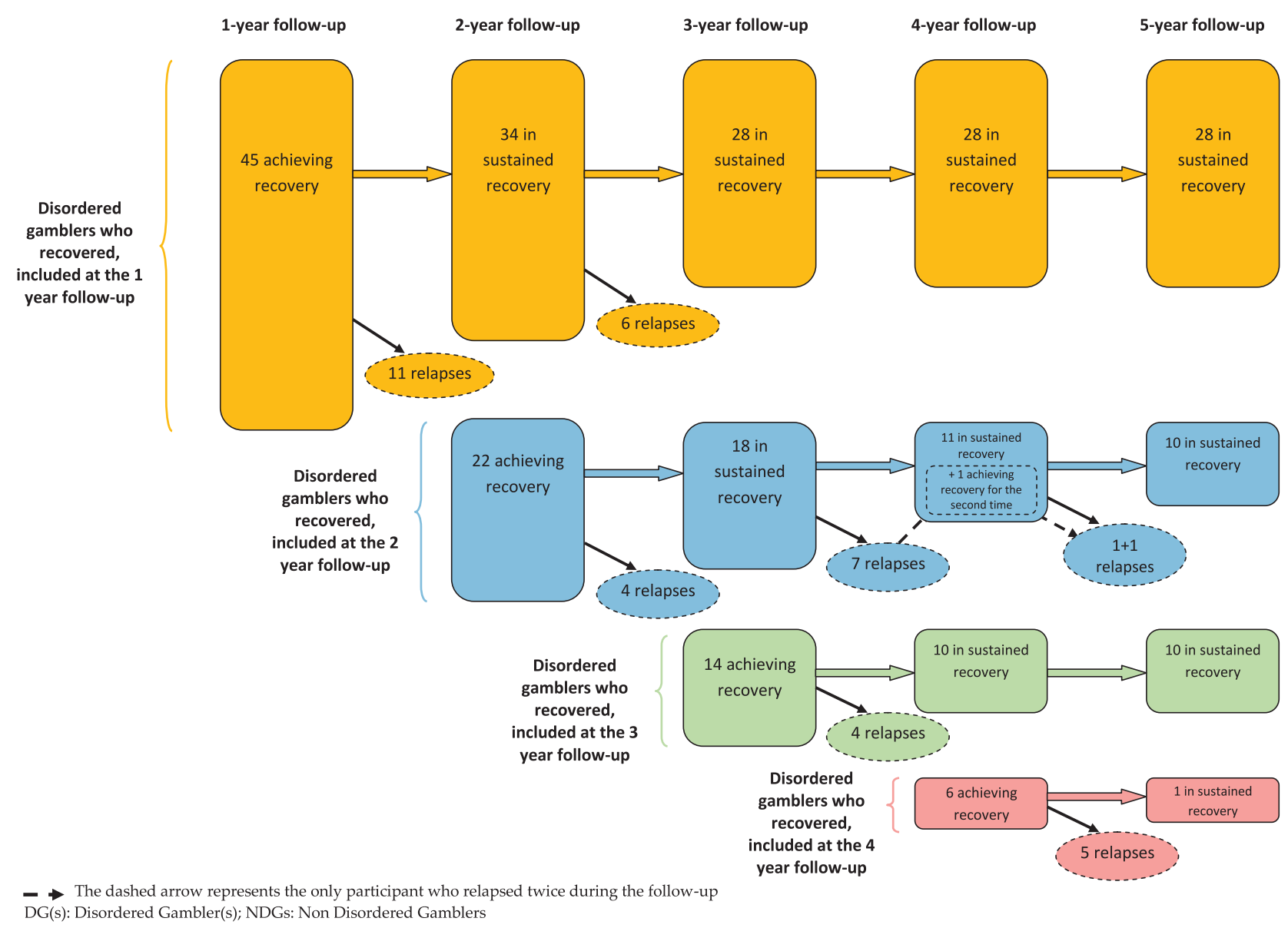

Fig. 2. Schematic representation of the observed transitions throughout the follow-up

Gambling disorder diagnosis and severity. Initially, the distinction between participants with and without GD was made through an interview based on the DSM-IV diagnostic criteria for pathological gambling (APA, 1994, 2004). The diagnosis of GD was reassessed for this specific analysis according to the $5^{\text {th }}$ version of the DSM (APA, 2013, 2015). Table 1 illustrates the distribution of the participants according to the classification used.

Thus, for each visit, the presence of at least 4 criteria out of 9 indicated the presence of a GD. GD severity was specified by the number of diagnostic criteria met at baseline.

Table 1. Distribution of the participants according to the classification used at baseline $(N=87)$

\begin{tabular}{ccccc}
\hline & \multicolumn{3}{c}{ DSM-IV } \\
\cline { 2 - 5 } & & $<3$ (or absence of B) & $3-4$ & $\geq 5$ \\
\hline DSM-5 & $<4$ (or absence of B) & 8 & 4 & 0 \\
& $\geq 4$ & 0 & 16 & 59 \\
\hline
\end{tabular}

Note. DSM-IV: "Problem Gambling" when 3-4 criteria (out of 10) are met; "Pathological Gambling" when at least 5 diagnostic criteria (out of 10) are met. DSM-5: "Gambling Disorder" when at least 4 diagnostic criteria (out of 9) are met. Both in DSM-IV and DSM-5, the gambling behavior is not better explained by a manic episode (B).
Gambling disorder treatment. During their enrollment visit, participants were asked about treatment they may have received at some point in their life for a GD. They were not included if they had already received treatment, except in the case of those recruited from one of the addiction treatment centers, provided that they had started treatment less than six months before. Treatment then consisted of psychosocial interventions focused on gambling as well as the treatment of potential comorbid psychiatric disorders. At each followup visit, all participants were asked about treatment related to a GD they could have received since the previous visit. They were considered to have received treatment if they had attended at least one consultation.

Gambling habits. We collected information about the gambling course: age at first gambling experimentation and age of regular gambling. Regarding the previous year, participants were asked about their participation in various forms of gambling, monthly gambling expenditures, experience of abstinence for one month or more (regardless of the types of gambling games played), and self-perception of having gambling problems. The favorite type of game was identified according to the classification proposed by Boutin (Boutin, 2010), i.e., "pure chance games" (slot machines, scratch cards, etc.), "chance games with pseudo-skills" (sports and horse-race betting and blackjack), and "chance 
games with elements of skills but without the opportunity for long-term gains" (poker). Gamblers with a multigame profile were restricted to defining a single preferred gambling activity. The interview also allowed us to define the medium used for gambling (online or offline).

GABS. We used the revised version of the Gambling Attitude and Beliefs Survey (GABS-23) (Bouju et al., 2014), which offers the advantages of being shorter than the original GABS (Breen \& Zuckerman, 1999) and of exploring gambling-related cognitions through five dimensions (Strategies [GABS-S]: conviction in illusory gambling strategies assumed to increase the probability of winning, 4 items; within-session Chasing [GABS-C]: persistent gambling when losing or winning within a particular session of gambling, 5 items; Attitudes [GABS-A]: conviction in gambling attitudes thought to increase the probability of winning, 5 items; Luck [GABS-L]: belief in good or bad luck and in superstitions, 4 items; and Emotions [GABS-E]: emotional excitement provided by gambling, 5 items). All items are coded on a scale ranging from strongly disagree $=$ 0 to strongly agree $=3$. The raw subscale scores are obtained by adding the scores of the items composing each subscale and range from 0 to 12 or 15 .

- Clinical profile

MINI. The Mini International Neuropsychiatric Interview (MINI) is a short diagnostic structured interview that explores the main lifetime and current DSM-IV psychiatric disorders (Lecrubier et al., 1997; Sheehan et al., 1998). It includes assessment of anxiety, mood (plus current risk of suicide) and addictive disorders, and, to a lesser extent, psychotic disorders. Each of these variables is rated as "present" or "absent". For the present analysis, only current comorbidities were taken into account.

TCI-125. The shorter 125 -item version of the Temperament and Character Inventory (TCI) is frequently used to quickly assess personality traits (Chakroun-Vinciguerra, Faytout, Pélissolo, \& Swendsen, 2005; Cloninger, Svrakic, \& Przybeck, 1993). It measures seven dimensions based on four temperaments (Novelty Seeking [NS]: a tendency to respond with intense excitement to novel stimuli or to cues for potential rewards or potential relief of punishment, thereby activating/initiating behavior, 20 items; Harm Avoidance [HA]: a tendency to respond intensively to signals of aversive stimuli, thereby inhibiting/stopping behavior, 20 items; Reward Dependence [RD]: a tendency to respond intensely to signals of reward, especially social rewards, thus maintaining and continuing particular kinds of behavior, 15 items; and Persistence $[\mathrm{P}]$ : a tendency to persist with behavior that has been associated with either a reward or relief from punishment, 5 items) and three characters (SelfDirectedness [SD]: the ability to regulate and adapt behavior to the demands of a situation to achieve personally chosen goals and values, 25 items; Cooperativeness [C]: the degree to which a person is generally agreeable in their relations with other people, 25 items; and Self-Transcendence [ST]: which relates to the experience of spiritual aspects of the self, 15 items). All items are coded as true or false with the attribution of 0 or 1 point, respectively, according to the item. For each dimension, the score is calculated by the following formula to obtain a standardized mean: sum of the score of the items ${ }^{\star} 100 /$ number of items of the dimension. Scores of the dimensions range from 0 to 100 .

The dimensions related to temperament were assessed only at baseline because they are considered stable tendencies of personality, whereas the dimensions related to character were assessed at all assessment phases because they are acquired under the influence of apprenticeship, experience and environment.

\section{- Outcome measure}

The primary outcome measure was the GD condition: "relapse" was defined as the reoccurrence of GD (the presence of at least 4 criteria out of 9 according to the DSM-5 "Gambling Disorder" section) at the $\mathrm{N}+1^{\text {th }}$ visit following the absence of GD at the $\mathrm{N}^{\text {th }}$ visit, whereas "sustained recovery" was defined as the absence of GD (less than 4 criteria) at two consecutive follow-up visits.

\section{Statistical analyses}

All available follow-up visits performed after the first observed recovery (first transition from GD to no GD, which determined inclusion in the analysis) for a given gambler were taken into account to screen for a potential relapse. We converted the dataset such that each transition between two consecutive follow-up visits (presence/absence of a GD at the $\mathrm{N}^{\text {th }}$ visit $\rightarrow$ presence/absence of a GD at the $\mathrm{N}+1^{\text {th }}$ visit) represents an observation. Transitions were then classified into two categories: (i) "sustained recovery" (no GD $\rightarrow$ no GD) and (ii) "relapse" (no GD $\rightarrow$ GD). Transitions "GD $\rightarrow$ GD" and "GD $\rightarrow$ no GD" were not taken into account because they did not correspond to transitions through which gamblers had or could have relapsed. We should note that a power analysis was not conducted due to the exploratory nature of the study.

We provided a descriptive analysis of characteristics at baseline for the participants included in the analysis according to whether they had relapsed or not during the follow-up period.

Finally, we used a Markov model-based approach to investigate predictors of relapse, which was defined as the primary outcome. Predictors were included as part of the original pool of the JEU cohort but were restricted to only those that can evolve over time (marital status, employment status, current gambling behavior, maximum frequency of gambling, favorite type/medium of game, monthly gambling expenditures, gambling free period of over more than one month, gambling disorder treatment, GABS subscales, current comorbidities, and character dimensions). In the present analysis, the statistical units were not participants but transitions, and several transitions were observed for a given participant. As a consequence, data related to several 
transitions for a given participant were not independent. To take into account the nonindependence of observations, the effects of predictors were estimated with a jointed mixed-effect multivariate logistic regression with a shared random effect placed on the participant explaining the relapse between two consecutive visits. The predictors of an eventual relapse between visits $\mathrm{N}^{\text {th }}$ and $\mathrm{N}+1^{\text {th }}$ were data characterizing each participant measured at visit $\mathrm{N}^{\text {th }}$, estimated for each transition as the value at the beginning of the transition, to predict relapse at the previous visit. Such a strategy may be useful in estimating the risk of relapsing in the forthcoming year. These predictors were selected from a univariate analysis with a type I error fixed to $20 \%$ according to the method proposed by Hosmer and Lemeshow (2000). This made it possible to avoid testing all of the variables in the multivariate analysis (with the risk of obtaining a nonrobust analysis) while avoiding omitting important variables. In the multivariate analysis, the predictors were selected according to a stepwise backward procedure with the type I error value set at 5\% to select only predictors that contribute information to the model. Due to the exploratory framework of this work and the absence of formal guidelines for minimizing type I error in this context, we have not considered $\alpha$-risk correction.

As the sample included GD individuals receiving or not receiving treatment, treatment could be considered a confounding factor and was included in the multivariate logistic regression. Given that treatment may have influenced the impact of the predictors on relapse during interval $\mathrm{N}^{\text {th }} \rightarrow \mathrm{N}+1^{\text {th }}$, it was assessed at visit $\mathrm{N}+1^{\text {th }}$ to collect all treatment events that could have occurred during this interval. Odds ratios (ORs) and associated 95\% confidence intervals $\left(\mathrm{CI}_{95 \%}\right)$ were estimated for the final model to quantify the strength of the association between the factors selected and relapse. The goodness of fit of the model was tested with a nonsignificant $P$-value indicating a good fit of the model. The ability of the model to predict relapse was assessed from the area under the receiver operating characteristic (ROC) curve.

No imputation of missing data was performed and the "available case analysis" method was used. All statistical analyses were conducted using Stata v15 (Stata Corp, College Station, Texas, 2017).

\section{Ethics}

The JEU cohort was approved by the French Research Ethics Committee (CPP) and conducted in accordance with Good Clinical Practice Guidelines and the Declaration of Helsinki. Written informed consent was obtained from all participants.

\section{RESULTS}

\section{Description of the sample used for analysis}

Among the 87 participants included in this analysis, 49 remained free of GD at all available follow-up visits, whereas 38 relapsed $(43.7 \%)$ at least once.
For the participants who were considered in "sustained recovery", approximately three-quarters reported that they had gambled at least once during the follow-up period $(n=$ $37,75.5 \%)$. Gambling activity was reported at 77 follow-up visits out of 90 , i.e., $85.5 \%$ of the visits.

For the participants who relapsed, 24 had done so one year after the first observed recovery, 13 had done so two years after, 1 had done so three years after, and none had done so four years after. Relapse occurred on average 1.39 years $(s d=0.55)$ after the first observed recovery. Only one participant relapsed twice during the follow-up period.

The participants' characteristics at inclusion are presented in Table 2.

\section{Description of transitions}

Figure 2, 179 transitions were observed throughout the follow-up period, of which 39 were cases of relapse and 140 were cases of sustained recovery.

\section{Predictors of relapse}

The univariate analysis shows that more than half of the variables were associated with relapse at the 0.20 level of significance (Table 3).

The results from the joint mixed-effect multivariate logistic regression are presented in Table 4. Only two variables were found to be independently associated with relapse. Participants who had experienced at least one month of abstinence and those with high TCI self-directedness scores at the previous follow-up visit were less likely to relapse $\left(\mathrm{OR}=0.24, \mathrm{CI}_{95 \%}[0.07 ; 0.82], P=0.023\right.$ and $\mathrm{OR}$ $=0.97, \mathrm{CI}_{95 \%}$ [0.94; 0.99], $P=0.047$, respectively).

The goodness-of-fit test shows that the final model was well calibrated $(P$-value $=0.57)$. The area under the ROC curve is 0.70 , showing that the model discriminated well between the patients who relapsed and those who did not.

\section{DISCUSSION}

\section{Main results}

This five-year follow-up study focused on participants with GD who recovered and their subsequent course (relapse or sustained recovery). In particular, we investigated factors associated with relapse. Several key findings of this work should be highlighted.

First, we found a relatively high rate of relapse when considering individuals (43.7\%), which is lower when considering all of the observed transitions $(21.8 \%)$. To the best of our knowledge, relapse rates have mainly been reported in clinical studies assessing the efficacy of GD treatment (for example, see Pallesen, Mitsem, Kvale, Johnsen, \& Molde, 2005), which does not allow for comparisons with our results. Hodgins and el-Guebaly's study (Hodgins \& el-Guebaly, 2004) is particularly original in this regard, as it focused on a naturalistic sample of pathological gamblers who had recently quit gambling. Only $6 \%$ remained 
Table 2. Description of the selected participant characteristics at baseline $(N=87)$

\begin{tabular}{|c|c|c|c|}
\hline & $\begin{array}{r}\text { Participants with relapse }(n=38) \\
\text { Mean }(\mathrm{sd})\end{array}$ & $\begin{array}{l}\text { Participants with sustained recovery }(n=49) \\
\text { or } n \text { (percentage) }\end{array}$ & P-value \\
\hline \multicolumn{4}{|l|}{ Sociodemographic Characteristics } \\
\hline \multicolumn{4}{|l|}{ Structured interview } \\
\hline - Sex: males $(\%)[M D=0]$ & $23(61 \%)$ & $34(69 \%)$ & 0.52 \\
\hline - Age (years) $[\mathrm{MD}=0]$ & $48.8(10.6)$ & $46.6(14.0)$ & 0.42 \\
\hline - Marital status: living as a couple (\%) $[\mathrm{MD}=0]$ & $19(50 \%)$ & $29(59 \%)$ & 0.52 \\
\hline - Education level: > Grade $12(\%)[\mathrm{MD}=0]$ & $11(29 \%)$ & $20(36 \%)$ & 0.36 \\
\hline - Work status: in job $(\%)[\mathrm{MD}=1]$ & $17(45 \%)$ & $27(55 \%)$ & 0.40 \\
\hline - Level of income: >minimum wage (\%) $[\mathrm{MD}=0]$ & $21(55 \%)$ & $31(63 \%)$ & 0.60 \\
\hline \multicolumn{4}{|l|}{ Psychopathological characteristics } \\
\hline \multicolumn{4}{|l|}{ Current comorbidities (MINI) } \\
\hline - Mood disorders $[\mathrm{MD}=0]$ & $27(71 \%)$ & $22(49 \%)$ & 0.022 \\
\hline - Risk of suicide $[\mathrm{MD}=0]$ & $11(29 \%)$ & $15(31 \%)$ & 0.87 \\
\hline - Anxiety disorders $[\mathrm{MD}=0]$ & $22(59 \%)$ & $15(30 \%)$ & 0.011 \\
\hline - Alcohol or substance use disorders [MD $=0]$ & $16(42 \%)$ & $22(45 \%)$ & 0.79 \\
\hline \multicolumn{4}{|l|}{ Temperament and character (TCI-125) } \\
\hline - Harm avoidance $[\mathrm{MD}=1]$ & $55.5(28.7)$ & $47.2(23.3)$ & 0.14 \\
\hline - Novelty seeking $[\mathrm{MD}=1]$ & $56.8(18.2)$ & $52.8(18.1)$ & 0.31 \\
\hline - Reward dependence $[\mathrm{MD}=1]$ & $53.5(21.1)$ & $61.5(14.7)$ & 0.041 \\
\hline - Persistence $[\mathrm{MD}=1]$ & $53.7(30.5)$ & $52.5(30.8)$ & 0.86 \\
\hline - Self-directedness $[M D=1]$ & $56.1(17.8)$ & $63.1(18.6)$ & 0.082 \\
\hline - Cooperativeness $[\mathrm{MD}=1]$ & $66.7(17.0)$ & $75.8(11.0)$ & 0.004 \\
\hline - Self-transcendence $[\mathrm{MD}=1]$ & $38.6(27.6)$ & $36.8(23.9)$ & 0.037 \\
\hline \multicolumn{4}{|l|}{ Gambling characteristics } \\
\hline \multicolumn{4}{|l|}{ Current gambling disorder severity(structured interview) } \\
\hline - Number of DSM-5 diagnostic criteria met $[\mathrm{MD}=0]$ & $5.7(2.5)$ & $5.4(1.7)$ & 0.51 \\
\hline \multicolumn{4}{|l|}{ Current gambling habits (structured interview) } \\
\hline - Age at first gambling experimentation $[\mathrm{MD}=0]$ & $22.3(9.9)$ & $20.3(7.6)$ & 0.29 \\
\hline - Age of regular gambling [MD = 7] & $26.4(8.6)$ & $27.1(11.5)$ & 0.76 \\
\hline - Current gambling $[\mathrm{MD}=0]$ & $33(87 \%)$ & $36(73 \%)$ & \\
\hline \multicolumn{4}{|l|}{ - Favorite type of game $[\mathrm{MD}=0]$} \\
\hline - "pure chance games" & $26(76 \%)$ & $32(65 \%)$ & 0.94 \\
\hline - "chance games with pseudo-skills" & $10(26 \%)$ & $13(15 \%)$ & \\
\hline - "chance games with elements of skills, but..." & $2(5 \%)$ & $4(8 \%)$ & \\
\hline \multicolumn{4}{|l|}{ - Favorite medium of game $[\mathrm{MD}=7]$} \\
\hline - offline & $17(45 \%)$ & $26(53 \%)$ & 0.87 \\
\hline - online & $8(21 \%)$ & $12(24 \%)$ & \\
\hline - both & $11(29 \%)$ & $13(27 \%)$ & \\
\hline - Monthly gambling expenditures (in euros) $[\mathrm{MD}=1]$ & $380.40(401.16)$ & $278.17(479.13)$ & 0.30 \\
\hline - Gambling free period $>1$ month $[\mathrm{MD}=1]$ & $7(10 \%)$ & $21(43 \%)$ & 0.019 \\
\hline - Self-perception of having gambling problems $[\mathrm{MD}=0]$ & $24(63 \%)$ & $26(53 \%)$ & 0.35 \\
\hline \multicolumn{4}{|l|}{ Irrational beliefs and attitudes (GABS-23) } \\
\hline - Luck $[\mathrm{MD}=1]$ & $6.7(3.1)$ & $5.5(3.0)$ & 0.29 \\
\hline - Chasing [MD = 1] & $9.7(3.8)$ & $8.0(3.8)$ & 0.36 \\
\hline - Emotions $[\mathrm{MD}=1]$ & $9.9(3.6)$ & $7.3(3.6)$ & 0.44 \\
\hline - Attitudes [MD $=1]$ & $7.6(3.7)$ & $7.3(3.1)$ & 0.23 \\
\hline - Strategies [MD $=1]$ & $6.6(3.0)$ & $6.7(3.2)$ & 0.46 \\
\hline
\end{tabular}

Note: MD: missing data.

abstinent. It is important to note that relapse was defined in this study as returning to gambling, while we considered the recurrence of GD during the follow-up period. In this sense, it is particularly interesting to note that three-quarters of the participants who were considered to be in sustained recovery in our study reported that they had gambled at some time during the follow-up period, reinforcing the idea that full abstinence is not required to avoid relapse. Another study drawing our attention aimed to estimate the prevalence and incidence of problem gambling in the general population, distinguishing between the development of a new GD and relapse. With this in mind, outcomes were assessed by means of screening tools. The rate of relapse was measured as $22 \%$ (Abbott et al., 2018).

Second, relapse occurred more than one year after the first observed recovery. Our study was designed to ensure a five-year follow-up period that was long enough to observe delayed relapses. This finding is highly original and demonstrates the need to conduct a study with a long-term follow-up component solely to capture transitions, both in a naturalistic sample and in a treatment-seeking population. Follow-up assessment in the gambling literature does not often exceed two years (Mestre-Bach et al., 2019) and rarely applies longer periods (Carlbring, Degerman, Jonsson, \& Andersson, 2012; Hodgins \& el-Guebaly, 2010; Slutske et al., 2003; Williams et al., 2015). Not all of the participants in our study were in treatment, but for those who were, this result calls for continued treatment for a long period after achieving remission so that "lapse" does not change to "relapse". A meta-analysis of cognitivebehavioral interventions designed to reduce problem gambling found the number of sessions to be relatively small (approximately 18 sessions) as well as the length of follow-up periods (24 months for only 4 studies out of 25) 
Table 3. Data collected before a time interval during which a relapse is possible: univariates analyses $(N=87$ individuals $/ / 179$ observed transitions)

\begin{tabular}{|c|c|c|c|}
\hline & OR & {$\left[\mathrm{CI}_{95 \%}\right]$} & $P$-value \\
\hline \multicolumn{4}{|l|}{ Sociodemographic characteristics } \\
\hline - Marital status: living as a couple $(\%)[\mathrm{MD}=0]$ & 1.74 & {$[0.67 ; 4.50]$} & 0.26 \\
\hline - Working status: in job $(\%)[\mathrm{MD}=1]$ & & {$[0.43 ; 5.44]$} & 0.52 \\
\hline \multicolumn{4}{|l|}{ Psychopathological characteristics } \\
\hline - Mood disorders $[\mathrm{MD}=3]$ & 6.61 & {$[1.38 ; 31.71]$} & 0.018 \\
\hline - Risk of suicide $[\mathrm{MD}=1]$ & 1.37 & {$[0.50 ; 3.71]$} & 0.54 \\
\hline - Anxiety disorders $[\mathrm{MD}=0]$ & 1.81 & {$[0.51 ; 6.43]$} & 0.36 \\
\hline - Alcohol or substance use disorders $[\mathrm{MD}=0]$ & 2.54 & {$[0.97 ; 6.66]$} & 0.058 \\
\hline - TCI-125 Self-directedness [MD $=11]$ & 0.965 & {$[0.941 ; 0.991]$} & 0.008 \\
\hline - TCI-125 Cooperativeness $[\mathrm{MD}=11]$ & 0.966 & {$[0.936 ; 0.997]$} & 0.030 \\
\hline - TCI-125 Self-transcendence $[\mathrm{MD}=11]$ & 1.009 & {$[0.991 ; 1.027]$} & 0.32 \\
\hline \multicolumn{4}{|l|}{ Gambling characteristics } \\
\hline - Current gambling $[\mathrm{MD}=1]$ & 3.09 & {$[0.94 ; 10.20]$} & 0.064 \\
\hline - Maximum frequency of gambling $[\mathrm{MD}=1]$ & 1.67 & {$[0.84 ; 3.32]$} & 0.14 \\
\hline \multicolumn{4}{|l|}{ - Favorite type of game ("pure chance games") $[\mathrm{MD}=8]$} \\
\hline - "chance games with pseudo-skills" & 2.16 & {$[0.82 ; 5.73]$} & 0.12 \\
\hline - "chance games with elements of skills, but..." & 0.36 & {$[0.03 ; 4.13]$} & 0.41 \\
\hline - Favorite medium of game $[\mathrm{MD}=123]$ & 1.64 & {$[0.31 ; 8.68]$} & 0.56 \\
\hline - Monthly gambling expenditures (in euros) $[\mathrm{MD}=4]$ & 1.002 & {$[1.000 ; 1.003]$} & 0.012 \\
\hline - Gambling free period $>1$ month $[\mathrm{MD}=13]$ & 0.28 & {$[0.10 ; 0.77]$} & 0.014 \\
\hline - Gambling disorder treatment $[\mathrm{MD}=0]$ & 1.20 & {$[0.38 ; 3.84]$} & 0.76 \\
\hline - GABS-23 Luck [MD = 12] & 1.008 & {$[0.989 ; 1.028]$} & 0.40 \\
\hline - GABS-23 Chasing [MD = 12] & 1.039 & {$[1.013 ; 1.066]$} & 0.004 \\
\hline - GABS-23 Emotions [MD = 12] & 1.040 & {$[1.014 ; 1.066]$} & 0.002 \\
\hline - GABS-23 Attitudes [MD = 12] & 1.022 & {$[1.000 ; 1.045]$} & 0.055 \\
\hline - GABS-23 Strategies $[\mathrm{MD}=12]$ & 1.024 & {$[1.002 ; 1.047]$} & 0.030 \\
\hline
\end{tabular}

Note: [CI 95\%]: Confidence Interval of 95\%; MD: missing data; OR: Odds Ratio.

Each variable was collected for each observed transition, and MD represents the number of transition where the data is missing (out of a total of 179 observed transitions).

Table 4. Factors associated with relapse $(N=79$ individuals//154 observed transitions)

\begin{tabular}{lccr}
\hline Variables & Ajusted OR & {$\left[\mathrm{CI}_{95 \%}\right]$} & $P$-value \\
\hline Gambling free period $>1$ month & 0.24 & {$[0.07 ; 0.82]$} & 0.023 \\
Gambling disorder treatment & 1.12 & {$[0.27 ; 4.65]$} & 0.869 \\
Self-directedness & 0.97 & {$[0.94 ; 0.99]$} & 0.047 \\
\hline
\end{tabular}

Note: [CI 95\%]: Confidence Interval of 95\%; OR: Odds Ratio.

(Gooding \& Tarrier, 2009), which could be areas of improvement.

Third, we identified two factors associated with relapse that are both associated with a large effect size. On the one hand, experiencing an abstinence period of at least one month in the previous year seemed to be a protective factor. Participants were not asked about their motivations to quit gambling, at least temporarily, so we can only infer. This could reflect significant self-control capacity, which is effective in inhibiting impulses and extinguishing conditioned cue reactivity and cue-induced craving. Conversely, the abstinence period could be made possible by the use of temporary self-exclusion (Kotter, Kraplin, \& Buhringer, 2018). Other environmental factors (support from close relationships, a lack of money, a change in lifestyle, a new job, etc.) may also have an effect. On the other hand, having a high TCI-SD score at the previous follow-up visit also appears to be a protective factor. As previously noted by Muller et al. (2017), personality maturation might be a protective factor against relapse (Muller et al., 2017). Self-directedness is defined as the ability to regulate and adapt behavior to the demands of a situation to achieve personal goals and values. As reported by Prillwitz et al. (2018), it is conceptualized as the executive control component of personality, allowing individuals to stay focused on the attainment of long-term goals (Prillwitz et al., 2018). In their magnetic resonance imaging study, the authors demonstrated a positive relationship between the integrity of the white matter of the salience network and the TCI-SD scores of healthy participants. White matter consists largely of myelinated nerve fibers bundled into tracts and typically underlies the cortical gray matter. Efficient information processing between distal brain regions is thought to rely on the integrity of their interconnecting white matter tracts. The salience network refers to a suite of brain regions (the anterior cingulate and ventral anterior insular cortices) and should respond to homeostatically relevant stimuli and outcomes whether their valence is negative (penalizing) or positive (reinforcing) (Seeley, 2019). Impairment in the salience network is involved in the development and maintenance of addiction by assigning excessive salience to addiction-related cues 
(Antons, Brand, \& Potenza, 2020; Prillwitz et al., 2018). In another study, participants with low scores in self-directedness reported stronger salience interference (Dinica et al., 2016). Previous reports have outlined that low TCI-SD scores are associated with addictive disorders (Anghelescu et al., 2010; Cowie et al., 2019; Gierski et al., 2017; Kovacs et al., 2020; Steingrimsson, Carlsen, Lundstrom, Lundstrom, \& Nilsson, 2020), including GD (Claes et al., 2012; Janiri, Martinotti, Dario, Schifano, \& Bria, 2007; Moragas et al., 2015; Nordin \& Nylander, 2007). However, to our knowledge, only a few studies have explored the role of the selfdirectedness dimension in the course of the disease (Aragay et al., 2015; Granero et al., 2020; Jimenez-Murcia et al., 2015). In particular, it was found that individuals with low TCI-SD scores were at risk of poor outcomes six months after the end of treatment (Granero et al., 2020). Our study is the first to suggest the influence of a high TCI-SD score on sustained recovery. Surprisingly, receiving gambling treatment did not seem to be predictive of the outcome. This counterintuitive finding supports the fact that the self-recovery process reported by some authors (Hodgins, Stea, \& Grant, 2011) could help not only achieve recovery but also prevent relapse.

\section{Strengths and weaknesses}

These results must be viewed within the context of several limitations. First, participants were not assessed strictly at the time when relapse occurred. Indeed, data were collected during the previous follow-up visit. Second, we used several self-reports, which are a source of recall and social desirability bias, although this was reduced through the complementary use of standardized clinical interviews. Third, $40.7 \%$ of the eligible sample refused to participate in the follow-up assessment. Dropout is a crucial problem in interventional studies by destroying the comparability of groups but is less problematic in observational studies, in which groups are not comparable at baseline. Statistical analyses took into account differences in the composition of the groups, so dropout had a weak impact on the results. As they were free to withdraw their consent at any time without providing any reasons for doing so, we can only make suppositions regarding a lack of interest, a lack of time to devote to the study, the cessation of gambling activity, or even the development of a GD or relapse. In their naturalistic follow-up study, Hodgins and el-Guebaly found a quite similar attrition rate and found the impact of this attrition bias, as well as of other unmeasured biases, to be unclear (Hodgins \& el-Guebaly, 2010). Fourth, our study did not investigate some factors that could dynamically influence relapse, such as participants' goals regarding gambling or gambling craving. However, a recent study concluded that $45 \%$ of participants had changed their goals (abstinence vs. moderation) at least once during the follow-up period (Stea, Hodgins, \& Fung, 2015). Another study found craving to correlate negatively with length of abstinence (Tavares, Zilberman, Hodgins, \& el-Guebaly, 2005). Finally, due to the relatively limited sample size applied, the analysis probably lacks power, potentially leading to the incorrect conclusion that certain variables did not play any role in relapse. Replications of this study are needed to formally confirm the predictors of relapse. However, these limitations are compensated by the study's strengths. We focused on disordered gamblers in recovery to study the factors associated with potential subsequent relapse, defined as the reoccurrence of GD and not simply as the reoccurrence of gambling episodes. The novelty of our study lies in our use of this definition of "relapse" and, in contrast, of the definition of "sustained recovery". We voluntarily used a concept that differs slightly from "sustained remission" defined by the DSM-5 ("after full criteria for GD were previously met, none of the criteria for GD have been met during a period of 12 months or longer"). In research, the term "recovery" is often used synonymously with the term "remission" (White, 2012). However, the latter seemed too restrictive for our purposes. Moreover, our sample consisted of a broad range of gamblers at baseline (with and without $\mathrm{GD}$, with or without treatment, and engaged in various types of gambling activities). Our study was designed to ensure a follow-up period that was long enough to capture key-state changes such as relapse. We were also able to collect data on gambling, personality traits and psychiatric disorders over a relatively long period (6 years), which is quite rare in the literature. Furthermore, gambling and psychiatric disorders were diagnosed using standardized clinical interviews, guaranteeing their validity. Finally, several factors were considered possible relapse precipitants in a multivariate regression model, as recommended by Ledgerwood and Petry (2006).

\section{Perspectives}

By identifying factors associated with relapse, our results present clinical features that are of high interest for both the care management and relapse prevention of GD. On the one hand, improvements in self-directedness could be specifically targeted. It may be assumed that people with a high level of self-directedness experience a sense of responsibility, determination, and self-acceptance. This disposition could help disordered gamblers who have recovered to keep in mind their long-term goal of recovery and to overcome disturbances in salience attribution. Recent studies have concluded that this facet of self-maturity could be strengthened through dialectical behavior therapy (Bernheim et al., 2017) or mindfulness-oriented meditation (Campanella, Crescentini, Urgesi, \& Fabbro, 2014). Cognitive remediation interventions oriented toward executive control and attentional biases may also be a promising adjunct treatment (Challet-Bouju, Bruneau, VictorriVigneau, \& Grall-Bronnec, 2017). On the other hand, gamblers should be a break from gambling. In a previous paper, we reported that experiencing a one-month abstinence period could help gamblers remain social gamblers over time (Bruneau et al., 2016). The present findings suggest that this practice could also protect against relapse. Educating gamblers on the risks associated with their 
activity and encouraging them to set limits on the frequency and intensity of gambling are two responsible gambling principles that should be supported by the gambling industry (Blaszczynski et al., 2011). Prevention messages promoting the experience of a one-month abstinence period per year could be disseminated, perhaps through regulatory mentions associated with gambling advertising. From a relapse prevention perspective, disordered gamblers who have recovered should be encouraged by health care providers to experience regular long gambling-free periods, even if they do not have a goal of full abstinence.

Funding sources: The JEU cohort was supported by:

-The joint support of the French Inter-departmental Mission for the fight against drugs and drug addiction (MILDT) and the French National Institute of Health and Medical Research (INSERM), as part of the call for research projects launched by these two organizations in 2007

-A grant from the French Ministry of Health (PHRC 2009

- RCB 2008-A01188-47)

This research was conducted at the initiative of and coordinated by the Addictology and Psychiatry Department of Nantes University Hospital. Nantes University Hospital is the sponsor of this study. There were no constraints on publishing.

Author's contribution: Study concept and design: MGB, JBH, GCB. Analysis and interpretation of data: MGB, GCB. Statistical analysis: JBH. Obtained funding: MGB, GCB. Study supervision: $\mathrm{MGB}, \mathrm{GCB}$. Investigation (data collection): MGB, CD, LR, IC, ICB, CL, MA, JEU-Group, GCB. Drafting of manuscript: MGB, JBH, GCB. Critical revision: MGB, MGL, JC, JBH, GCB.

Conflict of interest: MGB, GCB and JC declare that the University Hospital of Nantes has received funding from the gambling industry (FDJ and PMU) in the form of a philantropic sponsorship (donations that do not assign purpose of use). Scientific independence towards gambling industry operators is warranted. There were no constraints on publishing.

LR declares that the Scientific Interest Group "Game and Society" (Universities Paris 13 SPC, Paris Nanterre, Paris Descartes and Paris Sorbonne) was created and is supported by the gambling industry (FDJ). Scientific independence towards gambling industry operators is warranted. There were no constraints on publishing.

ICB declares she has received ICB declares she has received travel reimbursement and honorarium for expert advice to Lilly, Lundbeck, Otsuka, Janssen.

MA declares he has received grants from Pharmaceutical Industry through donations to University of Bordeaux Foundation (Indivior, Lundbeck), and travel reimbursement and honorarium for expert advice to Indivior, Lundbeck, Pfizer, Bouchara-Recordati, Camurus.
MGL, CD, IC, CL, JBH declare that they have no conflicts of interest.

\section{CLINICAL TRIAL REGISTRATION DETAILS}

\section{NCT01207674}

\section{PRE REGISTRATION ON A PUBLICLY AVAILABLE PLATFORM PRIOR TO UNDERTAKING THE ANALYSIS}

The study was preregistered in the ClinicalTrials.gov database (ClinicalTrials identifier: NCT01207674). Our team has published a "study protocol" article, which describes the data collection and the statistical analysis plan. This article is in open access (Challet-Bouju et al., 2014//PMID: 25141820).

\section{REFERENCES}

Abbott, M., Romild, U., \& Volberg, R. (2018). The prevalence, incidence, and gender and age-specific incidence of problem gambling: Results of the Swedish longitudinal gambling study (Swelogs). Addiction, 113(4), 699-707. https://doi.org/10.1111/ add. 14083 .

Anghelescu, I., Klawe, C., Singer, P., Fehr, C., Hiemke, C., \& Quante, A. (2010). Low novelty seeking and high self directedness scores in alcohol-dependent patients without comorbid psychiatric disorders homozygous for the A10 allele of the dopamine transporter gene. The World Journal of Biological Psychiatry, 11(2 Pt 2), 382-389. https://doi.org/10.1080/ 15622970701775058.

Antons, S., Brand, M., \& Potenza, M. N. (2020). Neurobiology of cue-reactivity, craving, and inhibitory control in non-substance addictive behaviors. Journal of Neurological Sciences, 415, 116952. https://doi.org/10.1016/j.jns.2020.116952.

APA. (1994). Diagnostic and statistical manual of mental disorders (4th ed.). Washington DC, USA.

APA. (2004). Diagnostic and statistical manual of mental disorders (4th ed. text revised French version). Paris: Masson.

APA. (2013). Diagnostic and statistical manual of mental disorders (5th ed.). Washington, DC, USA.

APA. (2015). Diagnostic and statistical manual of mental disorders (5th ed. French version). Paris: Elsevier-Masson.

Aragay, N., Jimenez-Murcia, S., Granero, R., Fernandez-Aranda, F., Ramos-Grille, I., Cardona, S. (2015). Pathological gambling: Understanding relapses and dropouts. Comprehensive Psychiatry, 57, 58-64. https://doi.org/10.1016/j.comppsych.2014.10. 009.

Battersby, M., Oakes, J., McLaughlin, K., \& Baigent, M. (2010). The definition and predictors of relapse in problem gambling. Final Report. Retrieved from Adelaide. http://www.jogoremoto.pt/ docs/extra/T312xu.pdf. 
Bernheim, D., Becker, M., Gander, M., Lischke, A., Mentel, R., Buchheim, A. (2017). Influence and change of self-directedness in dialectical behavior therapy. Psychiatrische Praxis, 44(5), 266-273. https://doi.org/10.1055/s-0042-104096.

Billi, R., Stone, C. A., Marden, P., \& Yeung, K. (2014). The Victorian gambling study: A longitudinal study of gambling and health in Victoria, 2008-2012. Retrieved from Victoria, Australia. https://responsiblegambling.vic.gov.au/documents/ 77/Research-report-longitudinal-study-gambling-and-healthvictoria-20082012.pdf

Blaszczynski, A., Collins, P., Fong, D., Ladouceur, R., Nower, L., \& Shaffer, H. J. (2011). Responsible gambling: General principles and minimal requirements. Journal of Gambling Studies, 27(4), 565-573. https://doi.org/10.1007/s10899-010-9214-0.

Blaszczynski, A., \& Nower, L. (2002). A pathways model of problem and pathological gambling. Addiction, 97(5), 487-499. https://doi.org/10.1046/j.1360-0443.2002.00015.x.

Bouju, G., Hardouin, J. B., Boutin, C., Gorwood, P., Le Bourvellec, J. D., \& Feuillet, F. (2014). A shorter and multidimensional version of the gambling attitudes and beliefs survey (GABS-23). Journal of Gambling Studies, 30(2), 349-367. https://doi.org/10. 1007/s10899-012-9356-3.

Boutin, C. (2010). Le jeu: Chance ou stratégie? Choisir librement la place du jeu dans votre vie. Montréal: Les Editions de l'Homme.

Breen, R. B., \& Zuckerman, M. (1999). 'Chasing' in gambling behavior: Personality and cognitive determinants. Personality and Individual Differences, 27, 1097-1111. https://doi.org/10. 1016/S0191-8869(99)00052-5.

Bruneau, M., Grall-Bronnec, M., Venisse, J. L., Romo, L., Valleur, M., \& Magalon, D. (2016). Gambling transitions among adult gamblers: A multi-state model using a Markovian approach applied to the JEU cohort. Addictive Behaviors, 57, 13-20. https://doi.org/10.1016/j.addbeh.2016.01.010.

Campanella, F., Crescentini, C., Urgesi, C., \& Fabbro, F. (2014). Mindfulness-oriented meditation improves self-related character scales in healthy individuals. Comprehensive Psychiatry, 55(5), 1269-1278. https://doi.org/10.1016/j.comppsych.2014.03. 009.

Carlbring, P., Degerman, N., Jonsson, J., \& Andersson, G. (2012). Internet-based treatment of pathological gambling with a threeyear follow-up. Cognitive Behavioral Therapy, 41(2), 321-334. https://doi.org/10.1080/16506073.2012.689323.

Chakroun-Vinciguerra, N., Faytout, M., Pélissolo, A., \& Swendsen, J. (2005). Validation française de la version courte de l'Inventaire du Tempérament et du Caractère (TCI-125). Journal de Thérapie Comportementale et Cognitive, 15(1), 27-33. https:// doi.org/10.1016/S1155-1704(05)81209-1.

Challet-Bouju, G., Bruneau, M., Victorri-Vigneau, C., \& GrallBronnec, M. (2017). Cognitive remediation interventions for gambling disorder: A systematic review. Frontiers in Psychology, 8, 1961. https://doi.org/10.3389/fpsyg.2017.01961.

Challet-Bouju, G., Hardouin, J. B., Venisse, J. L., Romo, L., Valleur, M., \& Magalon, D. (2014). Study protocol: The JEU cohort study-transversal multiaxial evaluation and 5-year follow-up of a cohort of French gamblers. BMC Psychiatry, 14, 226. https:// doi.org/10.1186/s12888-014-0226-7.

Claes, L., Jimenez-Murcia, S., Aguera, Z., Sanchez, I., Santamaria, J., Granero, R. (2012). Eating disorders and pathological gambling in males: Can they be differentiated by means of weight history and temperament and character traits? Eating Disorders, 20(5), 395-404. https://doi.org/10.1080/10640266.2012.715517.

Cloninger, C. R., Svrakic, D. M., \& Przybeck, T. R. (1993). A psychobiological model of temperament and character. Archives of General Psychiatry, 50(12), 975-990. https://doi.org/ 10.1001/archpsyc.1993.01820240059008.

Cowie, M. E., Kim, H. S., Hodgins, D. C., McGrath, D. S., Scanavino, M. D. T., \& Tavares, H. (2019). Demographic and psychiatric correlates of compulsive sexual behaviors in gambling disorder. Journal of Behavioral Addictions, 8(3), 451-462. https://doi.org/10.1556/2006.8.2019.35.

Cowlishaw, S., Merkouris, S., Dowling, N., Anderson, C., Jackson, A., \& Thomas, S. (2012). Psychological therapies for pathological and problem gambling. The Cochrane Database of Systematic Reviews, 11, CD008937. https://doi.org/10.1002/ 14651858.CD008937.pub2.

Dinica, K., Demenescu, L. R., Lord, A., Krause, A. L., Kaiser, R., \& Horn, D. (2016). Self-directedness and the susceptibility to distraction by saliency. Cognition \& Emotion, 30(8), 1461-1469. https://doi.org/10.1080/02699931.2015.1070792.

el-Guebaly, N., Casey, D. M., Currie, S. R., Hodgins, D. C., Schopflocher, D. P., \& Smith, G. J. (2015). The leisure, lifestyle, \& lifecycle project (LLLP): A longitudinal study of gambling in Alberta. Retrieved from https://dspace.ucalgary.ca/bitstream/ handle/1880/50377/LLLP_Final_Report_Feb21_2015_V4.pdf; jsessionid=4227DE0FBBB8E9B810919B6C5EBAB907? sequence $=1$.

Echeburua, E., Gomez, M., \& Freixa, M. (2017). Prediction of relapse after cognitive-behavioral treatment of gambling disorder in individuals with chronic schizophrenia: A survival analysis. Behavior Therapy, 48(1), 69-75. https://doi.org/10. 1016/j.beth.2016.09.008.

Gierski, F., Benzerouk, F., De Wever, E., Duka, T., Kaladjian, A., \& Quaglino, V. (2017). Cloninger's temperament and character dimensions of personality and Binge drinking among college students. Alcoholism: Clinical and Experimental Research, 41(11), 1970-1979. https://doi.org/10.1111/acer.13497.

Gooding, A., \& Tarrier, N. (2009). A systematic review and metaanalysis of cognitive-behavioural interventions to reduce problem gambling: Hedging our bets? Behaviour Research and Therapy, 47(7), 592-607. https://doi.org/10.1016/j.brat.2009.04. 002.

Goslar, M., Leibetseder, M., Muench, H. M., Hofmann, S. G., \& Laireiter, A. R. (2019). Pharmacological treatments for disordered gambling: A meta-analysis. Journal of Gambling Studies, 35(2), 415-445. https://doi.org/10.1007/s10899-01809815-y.

Granero, R., Valero-Solis, S., Fernandez-Aranda, F., Gomez-Pena, M., Moragas, L., \& Mena-Moreno, T. (2020). Response trajectories of gambling severity after cognitive behavioral therapy in young-adult pathological gamblers. Journal of Behavioral Addictions, 9(1), 140-152. https://doi.org/10.1556/2006.2020. 00008.

Hodgins, D. C., \& el-Guebaly, N. (2004). Retrospective and prospective reports of precipitants to relapse in pathological gambling. Journal of Consulting and Clinical Psychology, 72(1), 72-80. https://doi.org/10.1037/0022-006X.72.1.72. 
Hodgins, D. C., \& el-Guebaly, N. (2010). The influence of substance dependence and mood disorders on outcome from pathological gambling: Five-year follow-up. Journal of Gambling Studies, 26(1), 117-127. https://doi.org/10.1007/s10899-009-9137-9.

Hodgins, D. C., Stea, J. N., \& Grant, J. E. (2011). Gambling disorders. Lancet, 378(9806), 1874-1884. https://doi.org/10.1016/ S0140-6736(10)62185-X.

Hosmer, D. W., \& Lemeshow, S. (2000). Applied logistic regression (2nd ed). New York: Wiley.

Janiri, L., Martinotti, G., Dario, T., Schifano, F., \& Bria, P. (2007). The gamblers' temperament and character inventory (TCI) personality profile. Substance Use \& Misuse, 42(6), 975-984. https://doi.org/10.1080/10826080701202445.

Jimenez-Murcia, S., Granero, R., Fernandez-Aranda, F., Arcelus, J., Aymami, M. N., \& Gomez-Pena, M. (2015). Predictors of outcome among pathological gamblers receiving cognitive behavioral group therapy. European Addiction Research, 21(4), 169-178. https://doi.org/10.1159/000369528.

Kotter, R., Kraplin, A., \& Buhringer, G. (2018). Casino self- and forced excluders' gambling behavior before and after exclusion. Journal of Gambling Studies, 34(2), 597-615. https://doi.org/10. 1007/s10899-017-9732-0.

Kovacs, I., Pribek, I. K., Demeter, I., Rozsa, S., Janka, Z., \& Demetrovics, Z. (2020). The personality profile of chronic alcohol dependent patients with comorbid gambling disorder symptoms. Comprehensive Psychiatry, 101, 152183. https://doi. org/10.1016/j.comppsych.2020.152183.

Ladouceur, R., Lachance, S., \& Fournier, P. M. (2009). Is control a viable goal in the treatment of pathological gambling? Behaviour Research and Therapy, 47(3), 189-197. https://doi.org/10. 1016/j.brat.2008.11.004.

LaPlante, D. A., Kleschinsky, J. H., LaBrie, R. A., Nelson, S. E., \& Shaffer, H. J. (2009). Sitting at the virtual poker table: A prospective epidemiological study of actual Internet poker gambling behavior. Computers in Human Behavior, 25(3), 711-717. https://doi.org/10.1016/j.chb.2008.12.027.

Larimer, M. E., Palmer, R. S., \& Marlatt, G. A. (1999). Relapse prevention. An overview of Marlatt's cognitive-behavioral model. Alcohol Research \& Health, 23(2), 151-160.

Lecrubier, Y., Sheehan, D., Weiller, E., Amorim, P., Bonora, I., Sheehan, K. H., et al. (1997). The Mini international neuropsychiatric interview (MINI), a short diagnostic structured interview: Reliability and validity according to the CIDI. European Psychiatry, 12, 224-231. https://doi.org/10.1016/S09249338(97)83296-8.

Ledgerwood, D. M., \& Petry, N. M. (2006). What do we know about relapse in pathological gambling? Clinical Psychology Review, 26(2), 216-228. https://doi.org/10.1016/j.cpr.2005.11. 008.

Mallorqui-Bague, N., Mestre-Bach, G., Lozano-Madrid, M., Fernandez-Aranda, F., Granero, R., \& Vintro-Alcazaz, C. (2018). Trait impulsivity and cognitive domains involving impulsivity and compulsivity as predictors of gambling disorder treatment response. Addictive Behaviors, 87, 169-176. https://doi.org/10. 1016/j.addbeh.2018.07.006.

Mallorqui-Bague, N., Vintro-Alcaraz, C., Verdejo-Garcia, A., Granero, R., Fernandez-Aranda, F., \& Magana, P. (2019). Impulsivity and cognitive distortions in different clinical phenotypes of gambling disorder: Profiles and longitudinal prediction of treatment outcomes. European Psychiatry, 61, 9-16. https://doi. org/10.1016/j.eurpsy.2019.06.006.

Marlatt, G. A., \& Gordon, J. R. (1985). Relapse prevention: Maintenance strategies in the treatment of addictive behaviors. New York: Guilford Press.

Mazar, A., Volberg, R. A., Williams, R. J., Stanek, E. J., \& Zorn, M. (2019). The MA gambling impact cohort: Analyses across three waves. Retrieved from https://www.umass.edu/seigma/sites/ default/files/MAGIC\%20Wave\%203\%20Report_Final_201909-12.pdf.

Mestre-Bach, G., Steward, T., Granero, R., Fernandez-Aranda, F., Del Pino-Gutierrez, A., \& Mallorqui-Bague, N. (2019). The predictive capacity of DSM-5 symptom severity and impulsivity on response to cognitive-behavioral therapy for gambling disorder: A 2-year longitudinal study. European Psychiatry, 55, 67-73. https://doi.org/10.1016/j.eurpsy.2018.09.002.

Moragas, L., Granero, R., Stinchfield, R., Fernandez-Aranda, F., Froberg, F., \& Aymami, N. (2015). Comparative analysis of distinct phenotypes in gambling disorder based on gambling preferences. BMC Psychiatry, 15, 86. https://doi.org/10.1186/ s12888-015-0459-0.

Muller, K. W., Wolfling, K., Dickenhorst, U., Beutel, M. E., Medenwaldt, J., \& Koch, A. (2017). Recovery, relapse, or else? Treatment outcomes in gambling disorder from a multicenter follow-up study. European Psychiatry, 43, 28-34. https://doi. org/10.1016/j.eurpsy.2017.01.326.

Nordin, C., \& Nylander, P. O. (2007). Temperament and character in pathological gambling. Journal of Gambling Studies, 23(2), 113-120. https://doi.org/10.1007/s10899-006-9049-x.

Nower, L., \& Blaszczynski, A. (2017). Development and validation of the gambling pathways questionnaire (GPQ). Psychology of Addictive Behaviors, 31(1), 95-109. https://doi.org/10.1037/ adb0000234.

Oei, T. P., \& Gordon, L. M. (2008). Psychosocial factors related to gambling abstinence and relapse in members of gamblers anonymous. Journal of Gambling Studies, 24(1), 91-105. https://doi.org/10.1007/s10899-007-9071-7.

Pallesen, S., Mitsem, M., Kvale, G., Johnsen, B. H., \& Molde, H. (2005). Outcome of psychological treatments of pathological gambling: A review and meta-analysis. Addiction, 100(10), 1412-1422. https://doi.org/10.1111/j.1360-0443.2005.01204.x.

Petry, N. M. (2003). A comparison of treatment-seeking pathological gamblers based on preferred gambling activity. Addiction, 98(5), 645-655. https://doi.org/10.1046/j.1360-0443.2003. 00336.x.

Potenza, M. N., Balodis, I. M., Derevensky, J., Grant, J. E., Petry, N. M., \& Verdejo- Garcia, A. (2019). Gambling disorder. Nature Reviews, 5, 51. https://doi.org/10.1038/s41572-019-0099-7.

Prillwitz, C. C., Ruber, T., Reuter, M., Montag, C., Weber, B., \& Elger, C. E. (2018). The salience network and human personality: Integrity of white matter tracts within anterior and posterior salience network relates to the self-directedness character trait. Brain Research, 1692, 66-73. https://doi.org/10.1016/j. brainres.2018.04.035.

Sander, W., \& Peters, A. (2009). Pathological gambling: Influence of quality of life and psychological distress on abstinence after cognitive-behavioral inpatient treatment. Journal of Gambling 
Studies, 25(2), 253-262. https://doi.org/10.1007/s10899-0099128-x.

Seeley, W. W. (2019). The salience network: A neural system for perceiving and responding to homeostatic demands. Journal of Neuroscience, 39(50), 9878-9882. https://doi.org/10.1523/ JNEUROSCI.1138-17.2019.

Sharpe, L. (2002). A reformulated cognitive-behavioral model of problem gambling. A biopsychosocial perspective. Clinical Psychology Review, 22(1), 1-25. https://doi.org/10.1016/s02727358(00)00087-8.

Sheehan, D. V., Lecrubier, Y., Sheehan, K. H., Amorim, P., Janavs, J., \& Weiller, E. (1998). The Mini-international neuropsychiatric interview (M.I.N.I.): The development and validation of a structured diagnostic psychiatric interview for DSM-IV and ICD-10. The Journal of Clinical Psychiatry, 59(Suppl. 20), 22-33; quiz 34-57.

Slutske, W. S., Jackson, K. M., \& Sher, K. J. (2003). The natural history of problem gambling from age 18 to 29. Journal of Abnormal Psychology, 112(2), 263-274. https://doi.org/10.1037/ 0021-843x.112.2.263.

Smith, D. P., Battersby, M. W., Pols, R. G., Harvey, P. W., Oakes, J. E., \& Baigent, M. F. (2015). Predictors of relapse in problem gambling: A prospective cohort study. Journal of Gambling Studies, 31(1), 299-313. https://doi.org/10.1007/s10899-013-9408-3.

Stea, J. N., Hodgins, D. C., \& Fung, T. (2015). Abstinence versus moderation goals in brief motivational treatment for pathological gambling. Journal of Gambling Studies, 31(3), 1029-1045. https://doi.org/10.1007/s10899-014-9461-6.

Steingrimsson, S., Carlsen, H. K., Lundstrom, E., Lundstrom, S., \& Nilsson, T. (2020). Problematic alcohol and drug use is associated with low self-directedness and cooperativeness. European Addiction Research, 1-9. https://doi.org/10.1159/000506473.

Tavares, H., Zilberman, M. L., Hodgins, D. C., \& el-Guebaly, N. (2005). Comparison of craving between pathological gamblers and alcoholics. Alcoholism: Clinical and Experimental Research, 29(8), 1427-1431. https://doi.org/10.1097/01.alc.0000175071. 22872.98.

Welte, J. W., Barnes, G. M., Wieczorek, W. F., Tidwell, M. C. O., \& Hoffman, J. H. (2007). Type of gambling and availability as risk factors for problem gambling: A Tobit regression analysis by age and gender. International Gambling Studies, 7(2), 183-198. https://doi.org/10.1080/14459790701387543.

Welte, J. W., Barnes, G. M., Wieczorek, W. F., Tidwell, M. C., \& Parker, J. C. (2004). Risk factors for pathological gambling. Addictive Behaviors, 29(2), 323-335. https://doi.org/10.1016/j. addbeh.2003.08.007.

Williams, R., Hann, R., Schopflocher, D. P., West, B., McLaughlin, P., White, N., et al. (2015). Quinte longitudinal study of gambling and problem gambling. Report prepared for the Ontario Problem Gambling Research Centre. Guelph, Ontario. https://opus.uleth.ca/bitstream/handle/10133/3641/ QLS-OPGRC-2015.pdf. 